\title{
Linking User Age and Stress in the Interruption Era: The Role of Computer Experience
}

\author{
Stefan Tams \\ HEC Montréal \\ stefan.tams@hec.ca
}

\begin{abstract}
The workforce is rapidly growing older; especially the number of older workers (60 years and over) is increasing sharply. At the same time, the number of interruptions mediated by modern information technologies is growing rapidly. These interruptions include, for example, instant messages and email notifications. Recent research has shown that interruptions have harmful consequences for workers as they can lead to stress. Interruptions might be especially problematic for older workers, implying severe problems for this fast-growing group of users regarding their well-being and performance at work. This study proposes that older workers perceive more interruption-based technostress than their younger counterparts because of differences in computer experience between older and younger individuals. Thus, the study answers recent calls for exploring users' age as a substantive variable in IS research, and it also contributes to the literature on technostress by demonstrating how technostress might affect certain groups of users more than others.
\end{abstract}

\section{Introduction}

Paula Vieuxos, who just turned 64, is required to use information and communication technologies (ICTs) to support her work as a sales manager. Like many older people, she has a positive attitude toward ICTs and believes they are useful for her job, but she faces trouble in using them effectively - in contrast to Frank, a 25-year-old sales agent who grew up surrounded by ICTs. Paula is especially bothered by frequent interruptions such as unexpected text messages and emails; as many older adults, she finds them disruptive to mental work. While Paula knows that she could improve her interaction with the technology slightly by using the few accessibility options for older people it provides, she resents being required to click on a handicap icon to access these options - after all, she is a proud senior citizen who considers herself to be in good health. As a result of these problems, Paula is frustrated and feels that technology threatens her well-being and workplace performance, assuming, "It's not for me, I am too old!" Many older people share her experiences and think the computer age has passed them by [1].

This vignette illustrates the potential interdependency of two emergent trends across the OECD countries: the pervasive growth of ICTs in organizations and the "graying" of the workforce [1].

Today's workforce has to deal with increasingly frequent interruptions mediated by IT, such as a relentless stream of instant messages (through Skype for business), email notifications, text messages, meeting reminders, task reminders, etc. These technology-mediated (T-M) interruptions are mediated through smartphones, laptops and other devices, all of which beep, buzz, and blink constantly. Thus, T-M interruptions call for workers' attention almost all the time. In fact, they now consume about a third of employees' work days, causing stress [2,3,4]. The stress linked to IT, also labeled technostress, can have negative consequences for workers in the forms of reduced well-being (for example, negative emotions) and lower performance on IT-based tasks $[5,6,7,8,9,10]$.

At the same time, the workforce is rapidly growing older; it is said to be graying $[11,12,13]$. According to the OECD, all of its member countries are experiencing fast aging populations and workforces $[12,14,15,16]$. In fact, the number of older workers has risen from 15,906,000 in the year 2000 to $24,548,000$ in 2012 across the OECD countries, a rise of more than $50 \%$ [17]. Notably, the OECD expects this trend to continue; the participation of older individuals in the workforce is expected to increase steadily over the next 30 years across the OECD member countries [11,12].

As workers grow older, cognitive and biological changes occur. These changes include, for example, challenges related to memory decline and the reduced ability to operate computer input devices [18,19,20]. As a result of these changes, older workers should be more at risk of being impacted negatively by T-M 
interruptions [1]. However, guidance is nascent for managers in terms of how to ascertain that older individuals can use IT with greater ease [21]. Such guidelines might improve older workers' well-being and performance at work and, in consequence, merit careful examination. Therefore, this study investigates the question of whether, how, and why age impacts technostress in an interruption context.

The next section develops our research model, explaining that age impacts technostress in an interruption context because of older peoples' deficits in a pertinent cognitive ability. This cognitive deficit reduces the amount of cognitive resources that older workers have available for computer-related work. The cognitive deficit of older compared to younger workers that we are examining here relates to the creation of knowledge structures that become hard-wired and, thus, could lighten the cognitive burden of computerrelated work. More specifically, we are referring here to computer experience, which automates the schemata in working memory that relate to operating a computer. As a result of this automation, fewer cognitive resources are needed for operating the computer. The axiom "practice makes perfect" illustrates this idea; as tasks become more automatic due to increasing experience, they demand fewer cognitive resources. Hence, if workers have more computer experience, they should need fewer cognitive resources for operating the hardware and software at their disposal and should, thus, have more resources left over for task-related information processing. However, there is reason to believe that older workers have less computer experience than their younger counterparts [1].

Computer experience as treated in this study is not simply an artifact of time and place; we suggest that there are systematic reasons for which older workers accumulate less computer experience than their younger counterparts, with negative consequences for the cognitive resources they have available to deal with interruptions at work. Besides, we argue that generations of older workers to come will have a deficit in computer experience, unless managers are made aware of the importance of developing relevant computer experience in their older employees. In doing so, we take into consideration that prior work has recognized the potential of computer experience to mitigate technostress [22] but that no study has yet explicitly examined this potential role of computer experience. The third section of the paper reports on the model testing and results. The paper ends with an account against age discrimination.

\section{Background and Hypotheses}

This research answers recent calls for more explicitly theorizing the role of age in IS phenomena [21]. A recent research agenda recommended that IS researchers should theorize "touch points of age" [21]. Touch points of age are theoretical points through which the age construct touches on various IS phenomena. For example, age might impact IS use or stress due to changes in cognitive abilities that occur as people grow older, such as changes in fluid intelligence [21]. This concept implies that the age construct should be modeled as an indirect cause of IS dependent variables, with a mediating variable that explains more precisely how and why age plays a role in a given IS phenomenon (i.e., how and why age impacts an IS dependent variable). Investigating the role of age in IS through touch points is crucial. By specifying touch points, such investigations avoid justifying age-related effects on IS dependent variables on the basis of stereo-typical accounts, which is done too often [21]. What is more, using touch points of age can shed some light on the theoretical nature of the role of age in IS phenomena. In the present study, we examine a touch point of age that could be particularly relevant in the context of computer-mediated work environments: older peoples' potential deficits in accumulating relevant computer experience.

We ground our research and its touch point of age in the Human Information Processing Model, which is concerned with the question of how much mental capacity task-related information processing requires. According to this model, experience is responsible for the perceptual encoding of environmental stimuli, essentially liking related pieces of information (e.g., information about how to operate a computer) so that cognitive processes (e.g., operating a computer) become automated. Additionally, we ground our research in the literature on cognitive aging [23,24], which is concerned with the cognitive changes that occur as people grow older.

The Human Information Processing Model combined with the literature on cognitive aging highlight the importance of working memory to the context of our study, for two main reasons: information processing takes place in working memory and working memory declines as people age. Working memory is a transitory storage and processing component in the brain that holds the information required for carrying out a given task [24]. For instance, once a phone number has been found on a Web site, it is held in working memory until it is fully dialed [24]. Notably, the capacity of working memory is strictly limited, at times to just one single piece of information [24]. Given this strict capacity limitation, 
T-M interruptions can easily interfere with the information processing related to a given task when they enter working memory. This is because interruptions draw working memory resources away from a task, leaving fewer resources for the processing of task-related information. In consequence, mental work on the task becomes slow and error-prone (e.g., slow and incorrect dialing of phone numbers or slow reading and writing), leading to stress [24].

To avoid stress by ensuring that enough cognitive resources are available to deal with interruptions and still continue with a given task, computer experience needs to be considered as a pertinent factor. According to the Human Information Processing Model, computer experience is an important factor in the context of our study as it might reduce the requirements of a task for working memory resources [23], leaving more resources for the processing of interruptions. The axiom "practice makes perfect" illustrates this idea, implying the following, simple idea: as tasks become more automatic due to increasing experience, they demand fewer working memory resources. Consequently, at high levels of experience, interruptions may draw working memory resources away from a task without disrupting task performance. Yet, despite the recognized potential of computer experience to mitigate technostress [22], research on the role of computer experience in the technostress phenomenon is lacking. Furthermore, recent technostress research has called for re-examining the role of age in technostress [22].

Regarding computer experience and age, it has been suggested that older people may generally have very limited or even no computer experience as it relates to contemporary IT [23]. This is because older people were educated in times when IT was less complex so that their mental models of how technology works (i.e., mental representations of the structure, features, and usage characteristics of technology) may be insufficient for, or may even interfere with, the effective use of modern IT [23]. This situation is likely to continue into the future given the rapidly changing, evolving nature of IT. Hence, older adults' mental models of how technology works may continuously be grounded in the past and, hence, outdated and incongruent with later technological developments [23]. As a result of this incompatibility, older people should be less likely to gain relevant computer experience than younger individuals [24].

As a result of their lower levels of computer experience, older individuals may require more working memory resources to accomplish computerbased tasks than their younger counterparts, potentially resulting in more stress. This is because the behavior performance (e.g., IT usage) of a novice tends to be slow and effortful, whereas the performance of a behavior by an experienced individual tends to be fast and effortless. In line with Cognitive Load Theory, experience impacts the capacity of working memory [25]: as individuals gain experience with a task, the schemata in working memory that link related pieces of information become automated so that fewer mental resources are needed to complete the task. Essentially, experience increases working memory capacity. Hence, experienced people can more effectively manage competing resource demands [25], such as demands from the task at hand plus competing demands from incoming interruptions. In consequence, experienced individuals should have more resources to spare for the processing of interruptions than people with less experience.

In sum, individuals with more computer experience should have more resources to spare for the processing of interruptions so that they should be less stressed in the context of T-M interruptions. More generally, we hold that T-M interruptions can be problematic due to the capacity limitation of working memory. However, computer experience can buffer against the negative consequences of T-M interruptions by reducing the requirements of computer-based tasks for cognitive resources, leaving more resources for the processing of interruptions. Yet, older compared to younger people may, generally, have lower levels of relevant computer experience, implying that they will perceive more stress.

We hypothesize that, in the context of $\mathrm{T}-\mathrm{M}$ interruptions, older individuals experience more technostress than younger people because of differences in computer experience. In other words, we hypothesize that age is positively associated with stress via differences in computer experience (i.e., computer experiences mediates the positive association between age and stress; see Figure 1). 
Figure 1. Research Model

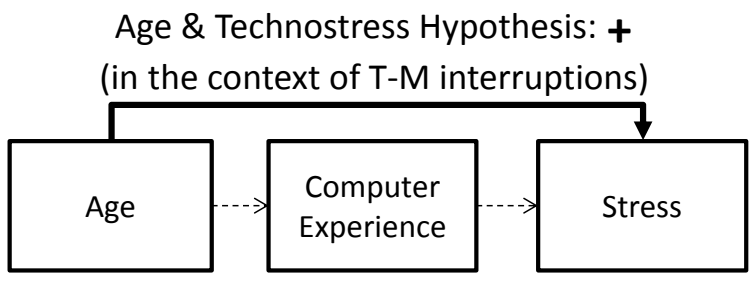

The line in bold represents our mediation hypothesis: when encountering T-M interruptions during a task, older people will report higher perceived stress levels than younger people because of lower levels of computer experience. In other words, age impacts stress via/through computer experience.

The dotted lines represent related direct effects, which are not the focus of our mediation hypothesis but are modeled here only to show what direct effects make up the mediation hypothesis.

\section{Method and Results}

We conducted a correlational study to investigate the relationship between age and stress in people who encounter T-M interruptions. To do so, we recruited younger and older participants and invited them to a computer laboratory, in which they performed a working memory task. During the working memory task, T-M interruptions in the form of instant messages appeared on the screen within specific time intervals. In line with past research on human information processing and cognitive functioning [23,24], we instructed the participants to ignore the interruptions so as to prevent confounding effects due to individual differences other than age. Participants' performance on the task was incentivized to increase the relevance of the task for the participants and their involvement. Half of our participants represented the group of younger workers (age<30) and half represented the group of older workers (age>60), implying that age was measured as a dichotomous variable with two categories: younger and older. This operationalization of age was consistent with research on cognitive aging in general, and with resource theories of aging in particular [26].

Computer experience refers to the extent to which people use computers [27]. We adapted a four-item scale for computer experience from prior research [27, please see Appendix 1]. To enhance the objectivity with which the participants rated the items, the response options were provided in terms of specific time intervals ranging from less than once a year to about every day.

Stress refers to the extent to which a person responds to a perceived misfit between the resources available for performing a task and the environmental resource demands [28]. Stress was captured via a stress scale. The scale (see Appendix 1) was an existing stress measure; we adapted a five-item scale from Galluch et al. [29] that asked the subjects how much stress they experienced in response to the task they had just performed.

The quality of our survey instrument was assessed by estimating the reliability and construct validity of the measurement items. SPSS version 21 was used to calculate all statistics, which evidenced good measurement properties. All alphas exceeded the 0.7 threshold (.93 and .91 for computer experience and stress, respectively), all AVE values were above 0.50, and the square root of the AVE for each construct was higher than the correlations between that construct and all other constructs in the model. Further, we used both procedural and statistical remedies to control for method bias [30]. No method bias was detected.

Since the instrument exhibited good measurement properties, we proceeded with a formal test of our hypothesis using the bootstrapping procedure developed by Preacher and Hayes [31]. More specifically, our age \& technostress hypothesis was evaluated using Hayes' PROCESS macro for testing indirect effects in SPSS [32]. We employed PROCESS model number 4 with a $95 \%$ confidence interval and 1,000 bootstrap resamples in SPSS version 21. The results supported our predictions: we found a significant, positive indirect effect of age on stress via computer experience. Since zero was outside the 95\% confidence interval, we can conclude with $95 \%$ confidence that the indirect effect of age on participants' stress levels via computer experience was different from zero $(b=0.244, S E=0.124, \mathrm{LL}=0.035$, $\mathrm{UL}=0.538, \mathrm{p}<0.05)$. Furthermore, post-hoc t-tests showed a significant difference in computer experience between older and younger people as expected, such that older individuals had less computer experience (mean difference $=-1.68, \mathrm{p}<.001$ ).

\section{Discussion and Conclusion}

Drawing on the Human Information Processing model and resource theories of cognitive aging, this study confirmed that older users experience more stress in today's technology-driven interruption era than younger ones. The study, further, demonstrated that this effect of age is due to differences in users' computer experience. Thus, this study makes an important theoretical contribution to IS research, explaining not only whether older users experience more technostress in response to T-M interruptions than younger users but also how and why they are more bothered by these interruptions (see Figure 2). 
Figure 2. Theoretical contribution: graying workforces, computer experience, T-M interruptions, and technostress

\section{Context: T-M interruptions}

Understanding of how and why age differences might exist before this research

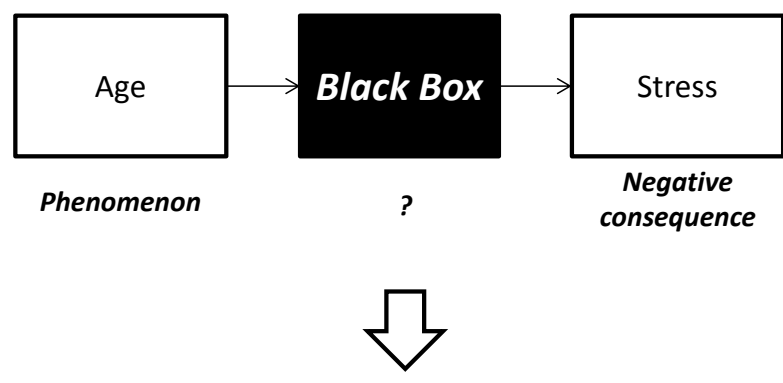

Understanding of how and why age differences might exist after this research

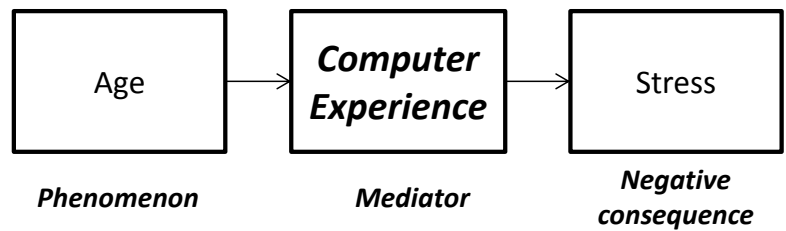

Managers may be advised to address the potential threats for employees and their productivity by using the findings from this research. For example, managers could invest in computer training to address the adverse effects of T-M interruptions on the health of older workers (and potentially on their productivity). Computer training may be a particularly effective strategy since it can greatly increase computer experience [27]. However, older workers tend to avoid computer training initiatives because of the short payback period for them [12]. Managers might need to incentivize computer training initiatives for older workers with monetary compensation or awards (e.g., a cash prize). Other ways of motivating them to participate in computer training initiatives might include taking their opinions into account, tying participation more closely to their career advancement, and setting clear goals for them.

Future research could unpack the role of computer experience further by examining, for example, to what extent wider socioeconomic issues such as the digital divide contribute to the lack of computer experience in older workers. To this end, future work could employ a mixed method design with an ethnographic study. Our findings highlight the opportunity to collect rich and powerful narratives from the people who are directly affected by T-M interruptions in their workplace.

Given the facts that the workforce is rapidly growing older across all OECD member countries and that modern technologies such as interruptions are proliferating, our findings are alarming. However, the findings should not be construed as encouraging discrimination against older workers or as encouraging any kind of stereotyping. Instead, they should be considered a means of facilitating the development of intervention strategies that can increase the well-being and productivity of a graying workforce. Ultimately, managerial interventions and technological developments are needed that offset the weaknesses and leverage the strengths of older workers to improve their well-being and productivity.

\section{Acknowledgements}

This research was supported by the Social Sciences and Humanities Research Council of Canada. 


\section{References}

[1] Tams, S.: The Role of Age in Technology-Induced Workplace Stress. Unpublished Doctoral Dissertation, Clemson University, USA (2011)

[2] Spira, J. B., Feintuch, J. B.: The cost of not paying attention: How interruptions impact knowledge worker productivity. Basex (2005)

[3] Tams, S., Thatcher, J., Grover, V., Pak, R.: Selective Attention as a Protagonist in Contemporary Workplace Stress: Implications for the Interruption Age. Anxiety, Stress, \& Coping, 28(6), 663-686 (2015)

[4] Tams, S., Thatcher, J., Ahuja, M.: The Impact of Interruptions on Technology Usage: Exploring Interdependencies between Demands from Interruptions, Worker Control, and Role-based Stress. In: Fred D. Davis et al. (eds.) Lecture Notes in information Systems and Organisation: Information Systems and Neuroscience, Volume 10, pp. 19-26. Springer, Heidelberg (2015)

[5] Ayyagari, R., Grover, V., Purvis, R.: Technostress: Technological antecedents and implications. MIS Quarterly, 35(4), 831-858 (2011)

[6] Riedl, R.: On the biology of technostress: Literature review and research agenda. The DATA BASE for Advances in Information Systems, 44(1), 18-55 (2013)

[7] Riedl, R., Kindermann, H., Auinger, A., Javor, A.: Technostress from a neurobiological per-spective-system breakdown increases the stress hormone cortisol in computer users. Business \& Information Systems Engineering, 4(2), 61-69 (2012)

[8] Riedl, R., Kindermann, H., Auinger, A., Javor, A.: Computer breakdown as a stress factor during task completion under time pressure: Identifying gender differences based on skin conductance. Advances in HumanComputer Interaction, Article ID 420169, doi: $10.1155 / 2013 / 420169$ (2013)

[9] Tams, S.: Challenges in Technostress Research: Guiding Future Work. Proceedings of the 21st Americas Conference on Information Systems, Puerto Rico, Article 38, 7 pages (2015)

[10] Tams, S., Hill, K., Ortiz de Guinea, A., Thatcher, J., Grover, V.: NeuroIS - Alternative or Complement to Existing Methods? Illustrating the Holistic Effects of Neuroscience and Self-reported Data in the Context of Technostress Research. Journal of the Association for Information Systems, 15(10), Article 1, 723-753 (2014)

[11] OECD: Work-force ageing in OECD countries. In OECD employment outlook 1998. Paris, France: OECD Publishing, 123-151 (1998)
[12] OECD: Helping older workers find and retain jobs. In Pensions at a Glance 2011: Retirement-Income Systems in OECD and G20 Countries. Paris, France: OECD Publishing, 67-79 (2011)

[13] Pham, S.: The Graying Work Force. The New York Times. Retrieved from

http://newoldage.blogs.nytimes.com/2010/11/30/the-grayingworkforce/?_php=true\&_type $=$ blogs\&_r $=0(2010$, November 30)

[14] OECD: The ageing challenge. In Ageing and the Public Service: Human Resource Challenges. Paris, France: OECD Publishing, 7-28 (2007)

[15] OECD: OECD Employment Outlook 2013. Paris, France: OECD Publishing (2013)

[16] OECD: Editorial. In International Migration Outlook 2013. Paris, France: OECD Publishing, 9-10 (2013)

[17] OECD: Labour market statistics: Labour force statistics by sex and age. In OECD Employment and Labour Market Statistics (Database, 2010)

[18] Charness, N., Holley, P., Feddon, J., Jastrzembski, T.: Light pen use and practice minimize age and hand performance different in pointing tasks. Human Factors, 46(3), 373-384 (2004)

[19] Darowski, E. S., Helder, E., Zacks, R. T., Hasher, L., Hambrick, D. Z.: Age-related differences in cognition: The role of distraction control. Neuropsychology, 22(5), 638-644 (2008)

[20] Salthouse, T. A., Babcock, R. L.: Decomposing adult age differences in working memory. Developmental Psychology, 27(5), 763-776 (1991)

[21] Tams, S., Grover, V., Thatcher, J.: Modern Information Technology in an Old Workforce: Toward a Strategic Research Agenda. Journal of Strategic Information Systems, 23(4), 284-304 (2014)

[22] Tarafdar, M., Qiang, T. U., Ragu-Nathan, B., \& RaguNathan, T. (2007). The impact of technostress on role stress and productivity. Journal of Management Information Systems, 24(1), 301-328.

[23] Fisk, A. D., Rogers, W. A., Charness, N., Czaja, S. J., Sharit, J. 2009. Designing for Older Adults: Principles and Creative Human Factors Approaches, US: Taylor and Francis.

[24] Wickens C. D., Lee J., Liu Y. D., \& Becker, S. G. (2004). Introduction to Human Factors Engineering, NJ: Prentice Hall.

[25] Sweller, J. 1994. "Cognitive load theory, learning difficulty. and instructional design," Learning and Instruction (4:4), pp. 295-312. 
[26] Smith, A. D. 1996. "Memory," Handbook of the psychology of aging (4th ed.). In T. A. Salthouse (Ed.), San

Diego, CA US: Academic Press, pp. 236-250.

[27] Harrison, A. W., and Rainer Jr., R. K. 1992. "The influence of individual differences on skill in end-user computing," Journal of Management Information Systems (9:1), pp. 93-111.

[28] Lazarus, R. S. 1999. Stress and emotion: A new synthesis, New York, NY US: Springer Publishing Co.

[29] Galluch, P. S., Grover, V., \& Thatcher, J. B. (2015). Interrupting the Workplace: Examining Stressors in an Information Technology Context. Journal of the Association for Information Systems, 16(1), 1.

[30] Podsakoff, P. M., MacKenzie, S. B., Lee, J., \& Podsakoff, N. P. (2003). Common method biases in behavioral research: A critical review of the literature and recommended remedies. Journal of Applied Psychology, 88(5), 879-903.

[31] Preacher, K. J., \& Hayes, A. F. (2004). SPSS and SAS procedures for estimating indirect effects in simple mediation models. Behavior Research Methods, Instruments \& Computers, 36(4), 717-731.

[32] Hayes, A. F. (2013). Introduction to mediation, moderation, and conditional process analysis: A regressionbased approach. Guilford Press. 


\section{Appendix 1 - Measurement Items}

\section{We used likert-type scales ranging from strongly disagree to strongly agree}

Computer Experience [27]

- On average, how frequently do you use a word-processing package (for example, Microsoft Word) on a computer?

- On average, how frequently do you use computer packages such as spreadsheets (for example, Microsoft Excel) or data management software?

- On average, how frequently do you use a computer for communicating with others (for example, through e-mail, instant messages, Facebook)?

- On average, how frequently do you use Internet browsers such as Mozilla FireFox, Internet Explorer and Google Chrome?

Stress [29]

- I felt strain due to the task demands.

- I felt emotionally drained from working on the memory task.

- I felt used up due to the task demands.

- I felt fatigued due to the task demands.

- I felt burned out from working on the memory task. 